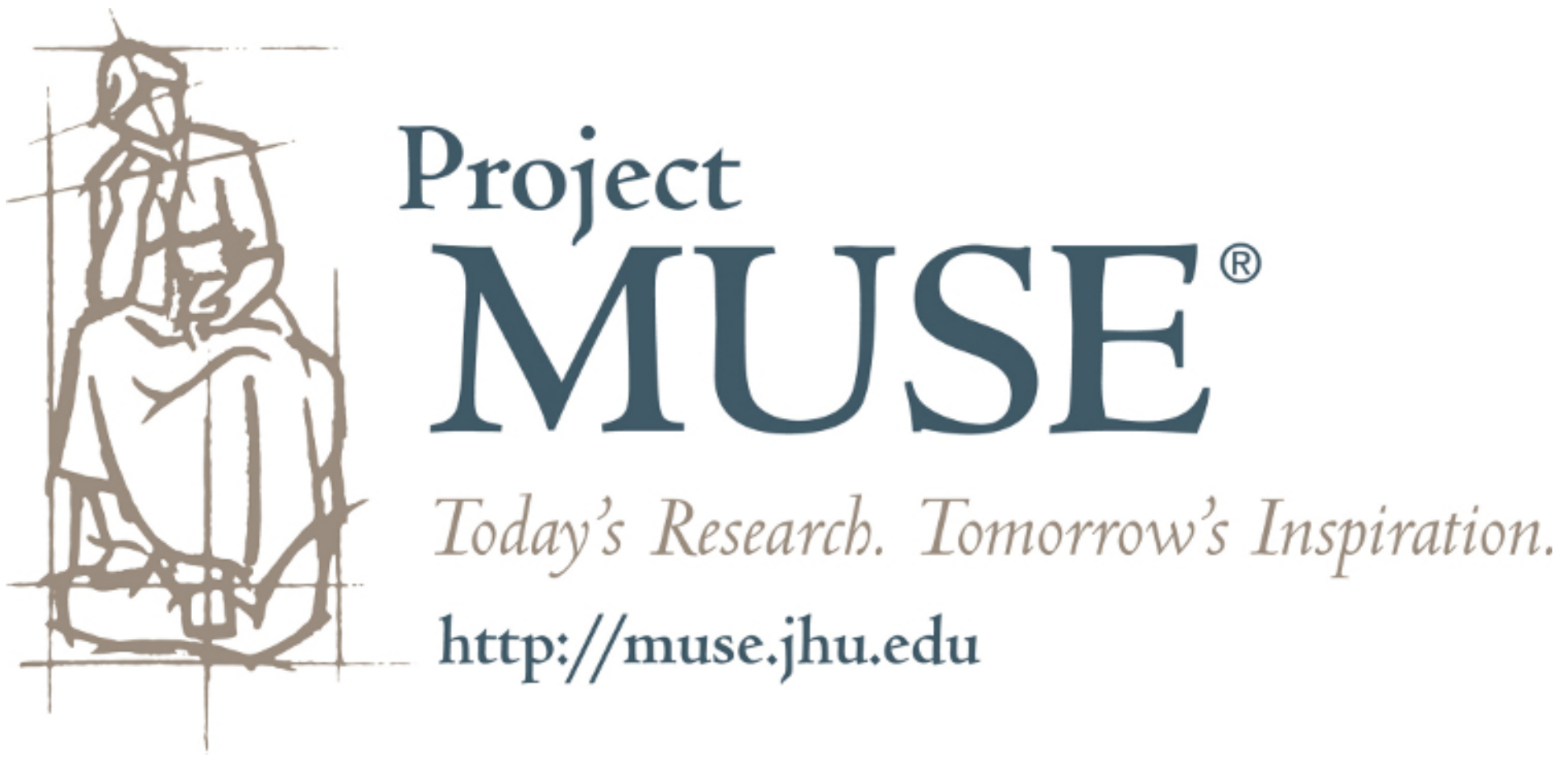




\title{
Socioeconomic Inequalities in Access to Health Care: Examining the Case of Burkina Faso
}

\author{
Chukwumezie O. Okolo, RPh, MBA, MSc \\ Daniel D. Reidpath, $\mathrm{PhD}$ \\ Pascale Allotey, $\mathrm{PhD}$
}

\begin{abstract}
The past decade has recorded remarkable interest in socioeconomic inequalities in health care. A multivariate analysis of the World Health Survey data for Burkina Faso was conducted using STATA. This included questions on household economic factors, perceived need, and access to health care. Poverty was defined using Principal Components Analysis. There was no significant difference in perceived need on the basis of poverty or gender. The less poor accessed health care more than the poor, but this difference was significant only among males. Respondents who lived in urban areas accessed health care more than those in rural areas, but this difference was significant only among females. We argue that health care financing arrangements affect self-reported need and access to health care. Even when they perceive need, the poor do not access care, probably because of cost, exacerbated by non-availability of readily accessible health care facilities.
\end{abstract}

Key words: Burkina Faso, low-income country, poverty, health disparities, principal components analysis, perceived need, self-reported access.

$\mathrm{I}^{\mathrm{n}}$ $n$ recent decades, there has been considerable interest in population health inequities and their association with socioeconomic status (SES). Several authors have demonstrated these inequities as a gradient in different countries using different outcome measures. ${ }^{1-10}$ There is now a reasonably well accepted view in the literature that as wealth increases, so too does the tendency for self-reported morbidity ${ }^{11-13}$ and the utilization of health services. ${ }^{14-17}$ The former view is not completely uncontested, ${ }^{18}$ and appears partially to depend on the health condition and the social context. ${ }^{18}$ Social gradients in self-reported morbidities have, however, been observed in both developed ${ }^{1,19,20}$ and developing ${ }^{11}$ countries. It is widely accepted, therefore, that the wealthy have a greater capacity to access and utilize health services than the poor.

The strength of the patterns in self-reported morbidity and health service utilisation seems to attenuate somewhat where the state provides free health care. For instance,

CHUKWUMEZIE OKOLO is a Public Health (DrPH) researcher at Brunel University, London. DANIEL REIDPATH is a Professor of Population Health and PASCALE ALLOTEY is a Professor of Public Health, both at Monash University, Malaysia. Please address correspondence to Dr. Okolo at 717 Preston Drive, Royse City, TX 75189; mezieokolo@yahoo.com. 
among European countries, the inequality gap is smallest for Sweden, a fact that is attributable to the country's social democratic policies, which result in smaller societal inequities overall. ${ }^{1,21}$ Notably, however, the gradient exists even in Sweden. ${ }^{22-28}$

The gradient relationship under discussion is predicated on there being no minimum threshold of absolute wealth. This has mainly been demonstrated by dividing the population into $\mathrm{x}$-tiles based on some wealth indices, and then comparing the outcome or indicator of interest across the whole spectrum (from top to bottom on the socioeconomic hierarchy). Some authors prefer to look at the health gap rather than the gradient, ${ }^{10,29-35}$ that is, to focus on the differences between the worst off and everybody else (assuming that everybody else apart from the worst off enjoys equally good health). ${ }^{4,36,37}$

Numerous studies have looked at equity both within and between countries. ${ }^{10,38-46}$ Relatively few of these studies have focused on the world's poorest populations. A number of considerations may explain this, including the fact that most economically poor countries are also data-poor. Routine vital statistics are not reliable, if they are available at all, and the health information systems may be anything but viable. This makes it difficult to capture trends and monitor progress. However, it was hypothesized that observations in data-rich countries would apply to data-poor ones, ${ }^{1}$ so we decided to see if and to what extent this holds.

We looked at Burkina Faso, one of the least developed and poorest countries in the world. ${ }^{47}$ In 1987, Sierra Leone and Burkina Faso were equally ranked third from the bottom on the United Nations Development Programme (UNDP) Human Development Index. ${ }^{48}$ In recent years, Sierra Leone has been consistently ranked at the bottom, and Burkina Faso has maintained its position in the bottom three. In 2002, it was ranked 175th out of 177 countries. ${ }^{49}$ In 2005, it was ranked as one of the bottom two (176th)..$^{50}$ Unlike Sierra Leone, for which no significant population health surveys have been conducted, a number have been conducted in Burkina Faso, including Demographic and Health Survey (DHS) and the World Health Survey (WHS). These informed our choice of Burkina Faso for this study.

Burkina Faso. Geographically, Burkina Faso is landlocked, bounded in the north by Mali, in the south by Ghana, in the east by Niger and in the west by Cote d'Ivoire. With an estimated population of about 16 million (and an annual population growth rate of $3.109 \%$ ) in 2008, Burkina Faso had a young median age of 16.7 years, and a birth rate of 44.68 and a death rate of 13.59 per 1,000 population. It has a high total fertility rate of 6.34 children/ woman; an infant mortality rate of 86.02 deaths/1,000 population; and a low life expectancy of 52.55 years (Table 1).

Socioeconomic indicators show that Burkina Faso has a predominantly illiterate population: only $21.8 \%$ of people aged 15 years and over are able to read and write. Agriculture accounts for about $90 \%$ of their labour force by occupation, and $46.4 \%$ of the whole population lives below poverty line of less than US $\$ 1$ per day.

The health system in Burkina Faso is divided into 11 administrative health regions. ${ }^{51}$ In 1992, a health sector reform programme was begun based on the Bamako Initiative (BI). This reform focused on decentralization and implementation of cost recovery mechanisms, the supply of Essential Generic Drugs (EGD) and the liberalization of the health services. ${ }^{47}$ Table 1 captures some of the indicators of interest. 


\section{Table 1.}

\section{GENERAL DEMOGRAPHIC, HEALTH AND SOCIOECONOMIC INDICATORS, BURKINA FASO}

\begin{tabular}{|c|c|}
\hline \multicolumn{2}{|l|}{ Geography } \\
\hline Location & West Africa, north of Ghana \\
\hline National hazards & Recurring droughts \\
\hline Environmental current issues & $\begin{array}{l}\text { Droughts affecting agricultural activities, } \\
\text { population distribution and the economy }\end{array}$ \\
\hline \multicolumn{2}{|l|}{ Demographic } \\
\hline Population & 15,264,735 (July 2008 est.) \\
\hline Age structure & $\begin{array}{c}0-14 \text { yrs }(46.3 \%) ; 15-64 \text { yrs (51.1\%); } \\
65 \text { yrs and over (2.5\%) (2008 est.) }\end{array}$ \\
\hline Median age & 16.7 yrs (2008 est.) \\
\hline Population growth rate & $3.109 \%$ (2008 est.) \\
\hline Birth rate & 44.68 births/1,000 population (2008 est.) \\
\hline Death rate & 13.59 deaths/ 1,000 population (2008 est.) \\
\hline \multicolumn{2}{|l|}{ Health } \\
\hline Infant mortality rate & 86.02 deaths/1,000 population (2008 est.) \\
\hline Life expectancy at birth & $\begin{array}{l}52.55 \text { years (male } 50.67 \text { yrs, female } 54.49 \text { yrs) } \\
\text { (2008 est.) }\end{array}$ \\
\hline Total fertility rate & 6.34 children born/woman (2008 est.) \\
\hline HIV/AIDS adult prevalence rate & $4.2 \%$ (2003 est.) \\
\hline \multicolumn{2}{|l|}{ Socioeconomic } \\
\hline $\begin{array}{l}\text { Literacy (age } 15 \text { and above } \\
\text { who can read and write) }\end{array}$ & $21.8 \%$ \\
\hline Labour force (by occupation) & $\begin{array}{l}90 \% \text { agriculture, } 10 \% \text { industry and services } \\
\text { (2000 est.) }\end{array}$ \\
\hline Unemployment & $77 \%$ (2004 est.) \\
\hline Population below & \\
\hline poverty line & 46.4\% (2004 est.) \\
\hline
\end{tabular}

\section{Methods}

The relationship between poverty, perceived need for health care, and subsequent access to the needed care for adults and children were examined using data from the World Health Survey (WHS) for Burkina Faso.

Sample. World Health Survey data were available for all 72 countries that participated. In each country, a stratified, multi-stage cluster sample was employed to obtain nationally representative data. The World Health Organization has made these data available for secondary analyses. Unfortunately, adequate information was only available for the primary sampling unit (PSU) and not the secondary or subsequent sampling units. However, information on the strata was available as were sampling weights to correct for the probability of individual selection. 
Procedures. The survey instrument included questions on socio-demographic factors, household economic factors, and self-reported need for and access to and utilisation of health care services. The surveys were delivered face-to-face to an adult in the household, using an appropriately translated instrument (originally written in English and translated to the local language by means of interpreters). The participating adult also responded to questions about the need for health care services by all children younger than 12 years old in the household. The procedures are fully described elsewhere. ${ }^{52}$

Measures. The age and sex of survey participants were measured directly. Age was recorded in years and categorized into six groups.

Poverty. Poverty was measured at the household level, and was based on principal components analysis (PCA) of a parcel of reported household assets. ${ }^{53}$ This approach is now a well-accepted alternative in resource-poor setting, where the more difficult-tocollect household expenditure data are unavailable. ${ }^{6}$ Indices of poverty based on PCA have been found to be robust to variations in the assets included in the analysis, and distinguish well between poor, middle-income, and wealthy households. ${ }^{53}$

The WHS collected data on a range of household assets including the nature and condition of the dwelling (such as the type of toilet, the floor materials, availability of electricity) and portable assets (such as radios, refrigerators, bicycles, and motorcycles). For Burkina Faso, a PCA was conducted on a parcel of these 17 household assets. A relative index of poverty was then constructed by dividing the sample into quintiles of wealth (or poverty).

Outcome measures. The two outcome measures of interest related to the perceived need for health care and access to health care subsequent to a perceived need. Perceived need for health care was captured as a binary outcome of whether the participants responded that they ("or a child of theirs aged 12 years or less") perceived need for health care in the past 30 days $(1=$ Yes, needed care; $0=$ No). For those who did perceive a need for health care in the past 30 days, access to health care was captured as a binary response to the question "last time you [or a child] needed health care, did you get health care?" ( 1 = Yes; $0=$ No).

Data analysis. Design-based analyses were conducted taking account of stratification, clustering at the first stage, and the sampling probability. Logistic regression was used to analyse the relationship between relative poverty and the two outcomes of perceived need for health care, and access to health care. A two-stage process was used for the analysis. In the first stage, separate bivariate analyses were conducted examining the relationship between poverty, socio-demographic factors, and health care need and access. The multivariable relationship between poverty and self-reported health care need and access was examined, controlling for socio-demographic factors. All analyses were conducted in Stata10 using the appropriate svy commands. ${ }^{54}$

Study sample. A total of 4,804 cases were analysed. Those who reported that either they or their child aged 12 years or younger needed health care in the 30 days prior to survey were $1,242(25.86 \%)$ out of which $1,093(88.02 \%)$ accessed the care they needed. Disaggregated by gender, the sample consisted of 2,532 (52.7\%) males and 2,272 (47.3\%) females. Of all males, 723.2 (28.56\%) needed health care out of whom $643.4(88.97 \%)$ accessed the needed care. Of all the females, $519(22.84 \%)$ reported that they needed care, and 449.9 (86.7\%) of them accessed the needed care (Table 2). 


\section{Table 2.}

\section{SAMPLE DISTRIBUTION FROM WORLD HEALTH SURVEY DATA ANALYSIS}

Number Percentage (\%)

Sample size $(\mathrm{N})$

All who needed health care (male + female)

All who accessed needed care (male + female)

Males

Males who needed health care

Males who accessed needed care

Females

Females who needed health care

Females who accessed needed care

$\begin{array}{cl}4,804 & \\ 1,242 & 25.86 \\ 1,093 & 88.02 \\ 2,532 & 52.7 \\ 723.2 & 28.56 \\ 643.4 & 88.97 \\ 2,272 & 47.3 \\ 519 & 22.84 \\ 449.9 & 86.7\end{array}$

\section{Results}

The results are presented in Tables 3 and 4. Table 3 shows self-reported perceived need according to the poverty quintiles, gender, marital status, age group, setting, and whether a child or an adult needed care. Table 4 shows self-reported access to needed health care. Percentages as well as bivariate and multivariate odds ratio statistics were reported. Perceived need for care increased from $20.17 \%$ in the poorest quintile to $30.64 \%$ in the richest quintile. Bivariate analyses suggest that the least poor are 1.75 times more likely to report need $(\mathrm{OR}=1.83, \mathrm{p}<0.01$ in males; $\mathrm{OR}=1.65, \mathrm{p}<.05$ in females) than the most poor. However, the multivariate analyses (adjusted model) show no differences between them. Gender does not seem to be a significant predictor of self-reported need for health care, even though males reported more need than females in the unadjusted model $(\mathrm{OR}=1.35, \mathrm{p}<.01)$. Those whose spouse had died reported significantly more need than those who were separated $(\mathrm{OR}=0.28, \mathrm{p}<.05)$, especially among females $(\mathrm{OR}=0.08, \mathrm{p}<.05)$. Those who were middle-aged ( $30-59$ years) reported significantly less need than those 70 years and older. Among males, age did not seem to affect selfreported need, while among females only those $18-39$ years reported significantly less need than those 70 years and older $(\mathrm{OR}=0.47$ and 0.50 ; $\mathrm{p}<.05)$.

Those who lived in urban areas reported more need than those in rural areas, but this difference was significant only for females $(\mathrm{OR}=1.6, \mathrm{p}<.05)$. Similarly, children were reported to have needed more care than adults $(\mathrm{OR}=1.6, \mathrm{p}<.01)$, both by male respondents $(\mathrm{OR}=1.4, \mathrm{p}<.05)$ and females respondents $(\mathrm{OR}=1.81, \mathrm{p}<.01)$.

Access to care results are presented on Table 4 . Of all those who needed care, about $79 \%$ of the most poor and about $91 \%$ of the least poor accessed the needed care. Among females, there is no significant difference in access on the basis of poverty status. Among males, the least poor (wealthy) are about twice more likely to have received care than the most poor $(\mathrm{OR}=1.8 ; \mathrm{p}<.05)$. Overall, the multivariate analytic model shows that 


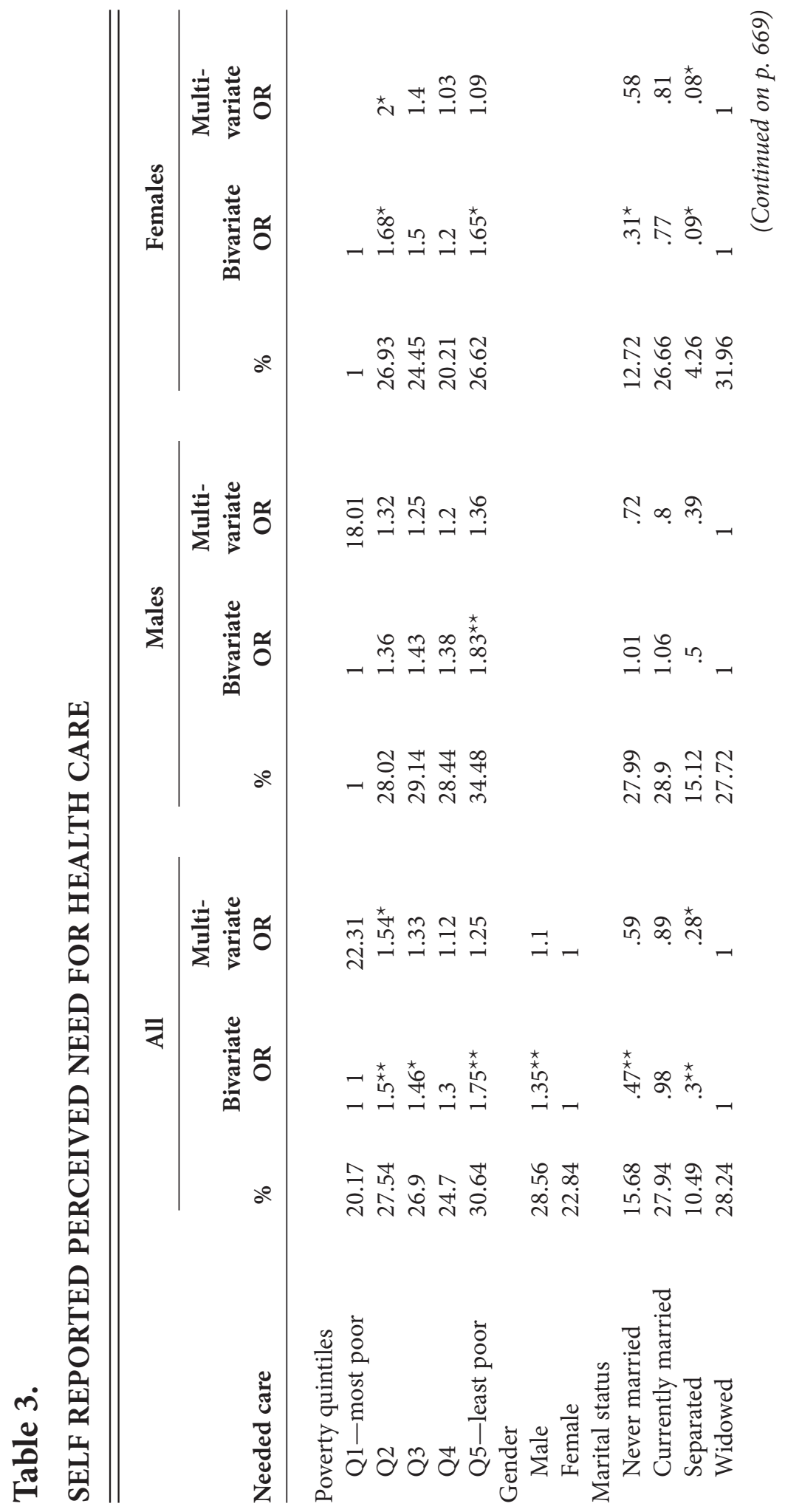




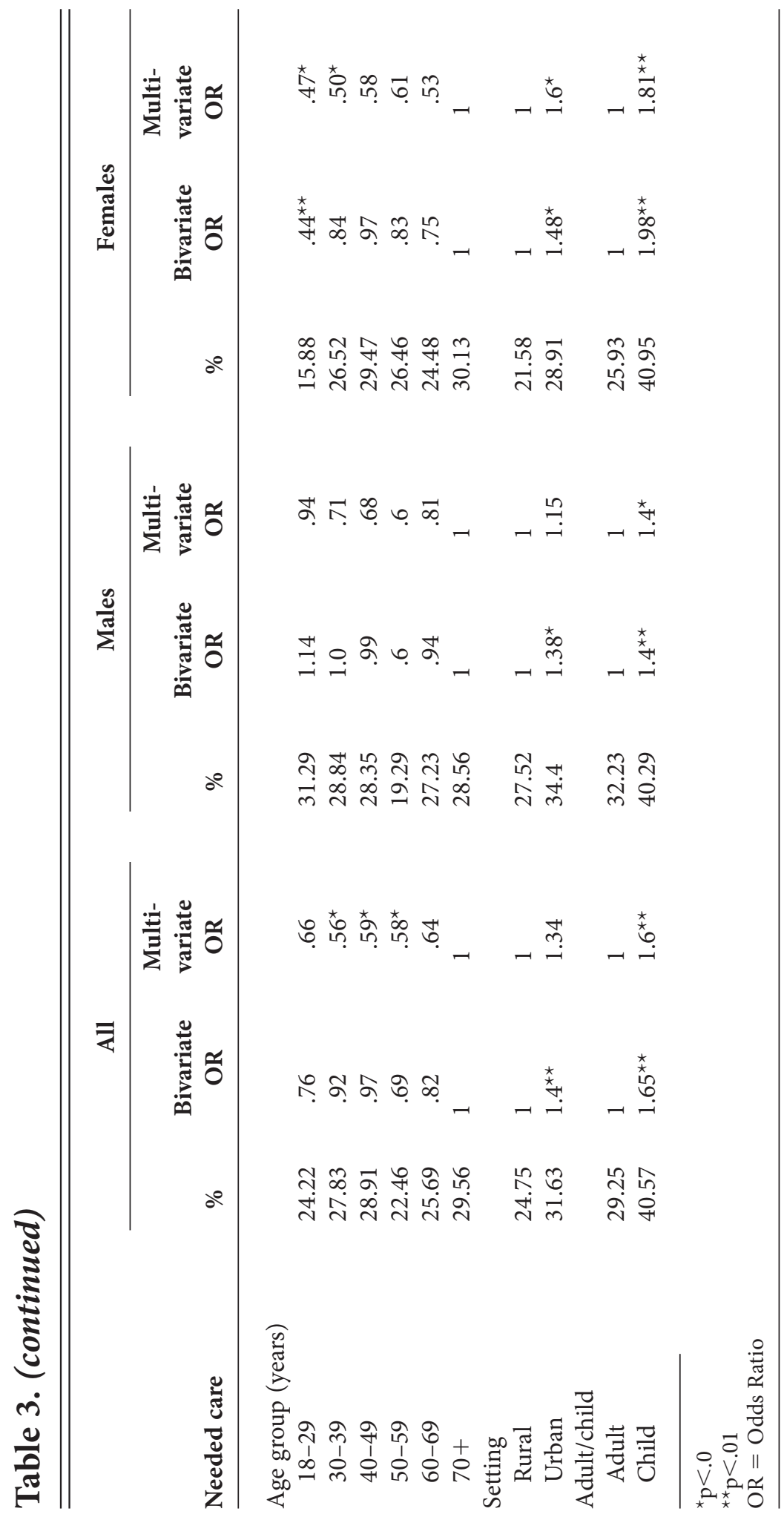


the least poor are 1.52 times more likely to have received needed health care than the most poor $(\mathrm{OR}=1.52 ; \mathrm{p}<.05)$.

There are no significant gender, marital status, or age group differences in access to health care. However, those who live in urban areas seem to have more access than those who live in rural areas, even though this difference is significant only in females $(\mathrm{OR}=1.55, \mathrm{p}<.05)$.

Children were reported to be more likely to have access to care than adults $(\mathrm{OR}=1.63$, $\mathrm{p}<.01$ ). However, males did not report any significant difference between children and adults while females reported that children were about twice more likely than adults to access care $(\mathrm{OR}=2.14, \mathrm{p}<.01)$.

\section{Discussion}

Our results show that $25.86 \%$ of respondents perceived need for health care in the recall period. This percentage may be considered high for a developing country, but agrees with previous studies. ${ }^{55}$ The result agrees also with the earlier study on the effect of socioeconomic status on the use of health services. ${ }^{55}$

Inequalities were observed, not for perceived need but for access to health care between the richest and the poorest. More remarkable, though, is that the gradient is not smooth (Figure 1), in contrast with those reported elsewhere. ${ }^{1,6,8,21}$ Despite the significant difference in access between the best off and the worst off, the gradient is unusual. These deviations from expectation are worth investigating further. Some possible explanations are discussed below.

Although proponents assumed otherwise, demand for health services has been shown to be price-elastic, especially among the poor. ${ }^{56-60} \mathrm{It}$ is possible that the poor are deterred from reporting need because most health care in Burkina Faso is still based on user-fees, which have been shown to be very regressive. Even in places where insurance schemes are available, they may not be affordable for the poor. ${ }^{61-64}$ Reasons to believe that user-fees are worsening the inequality gap between the poor and the rich have been documented ${ }^{65}$ and insurance schemes have not addressed the problem. Even if basic care is free, patients still must purchase most drugs at private pharmacies. ${ }^{60}$ Serious negative health effects are sure to follow if user fees prevent seriously ill patients from seeking or even reporting health care. ${ }^{66}$

There are some concerns about cost and quality of health care services in Burkina Faso (as in Cameroon). ${ }^{67}$ It has been reported that cost and perception of the quality of care are two major determinants of demand for health care services, especially because the people are very poor and out-of-pocket costs are very high. ${ }^{51}$ It has also been stated that access to health care is constrained by the ability to pay, ${ }^{47}$ because Burkina Faso is one of the countries in the region where common generic drugs are most expensive. ${ }^{47}$ The same paper reported that about $35 \%$ of people who did not seek health care they needed said that their failure to do so was because they couldn't afford it, while two-thirds said they had difficulties meeting their health expenses. Similar findings have been reported for Vietnam. ${ }^{68-70}$ Huge out-of-pocket costs could lead to less use of medical care, given other needs. ${ }^{71}$

Regarding quality of care, it was noted that the attitude of health care professionals is 


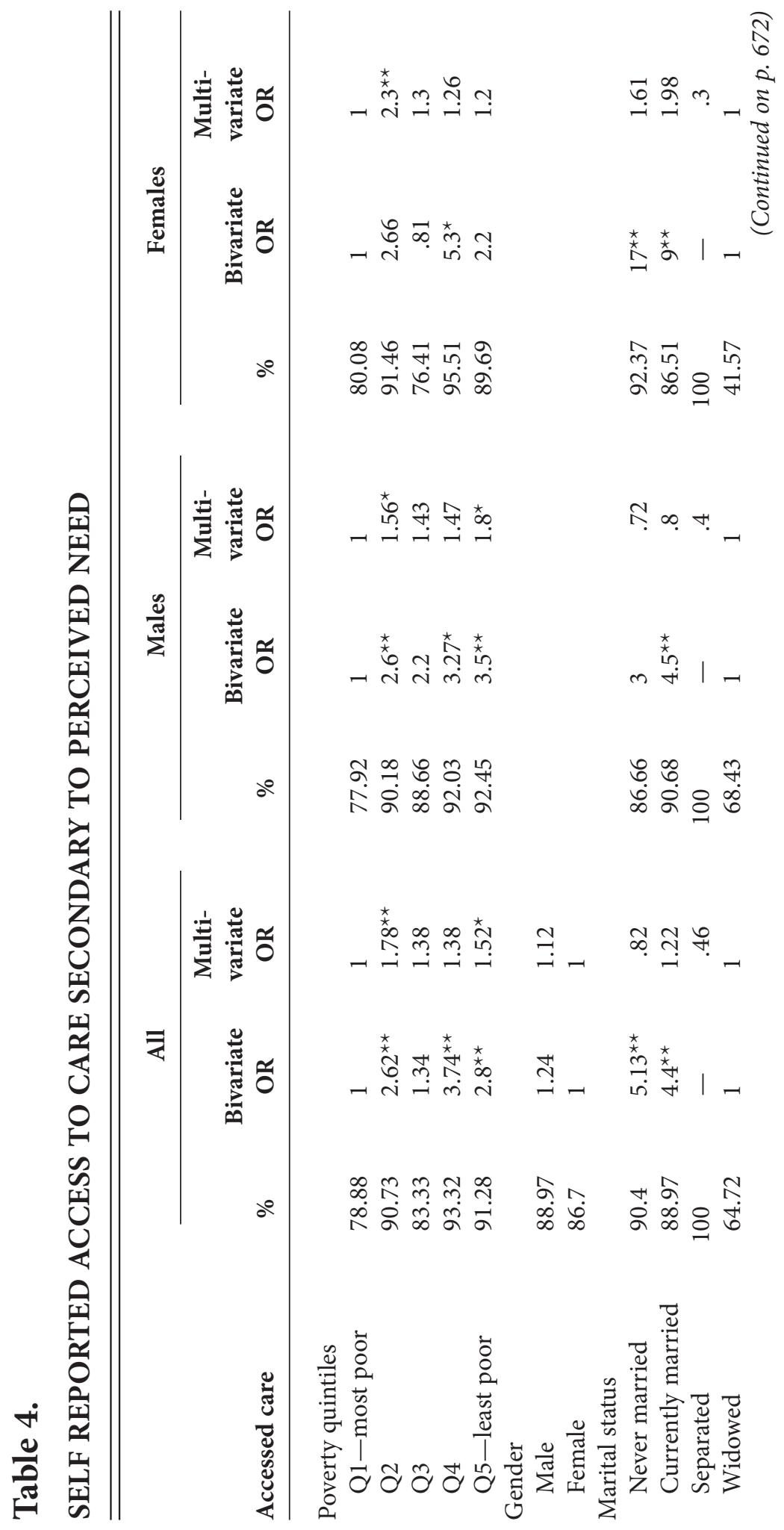




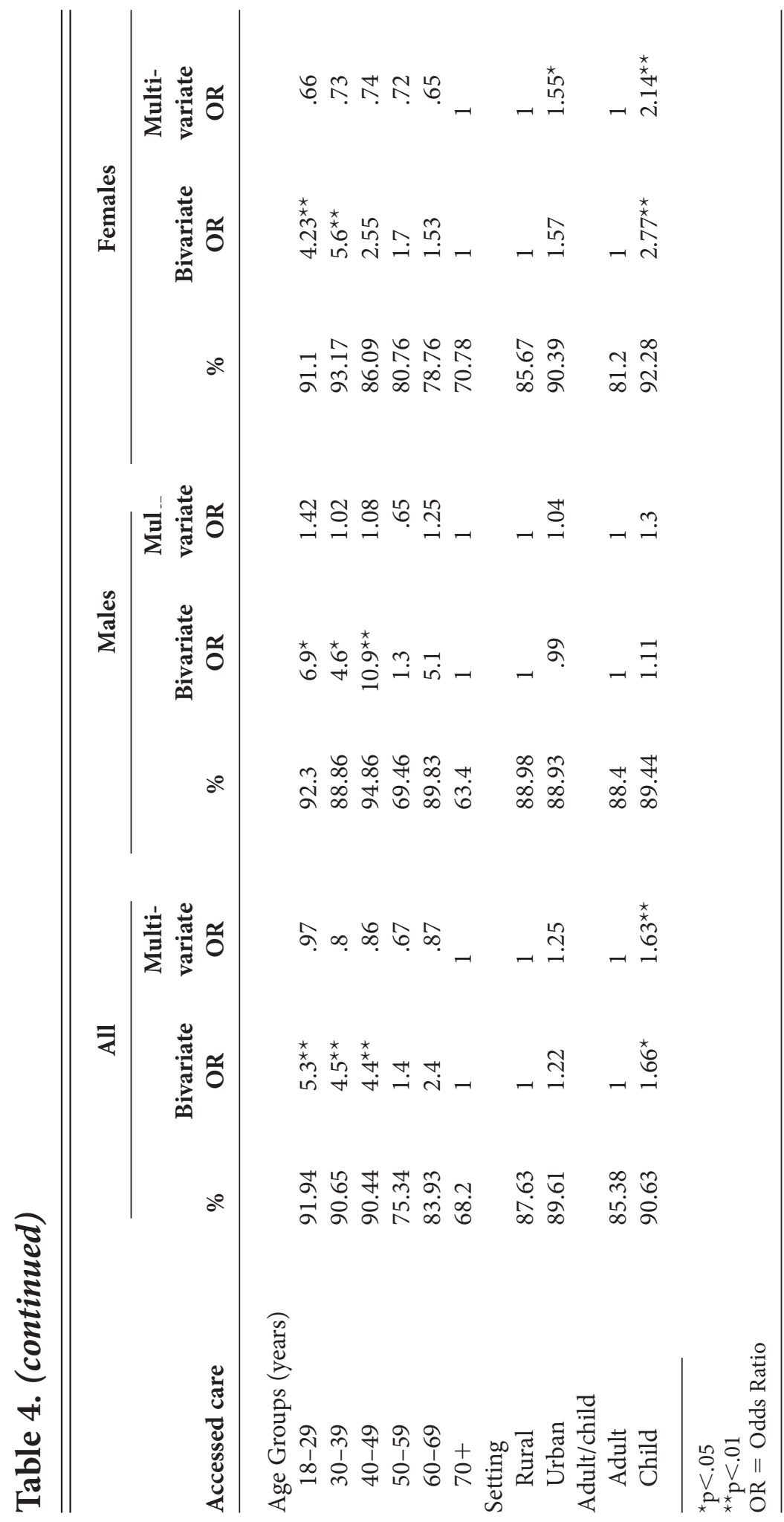




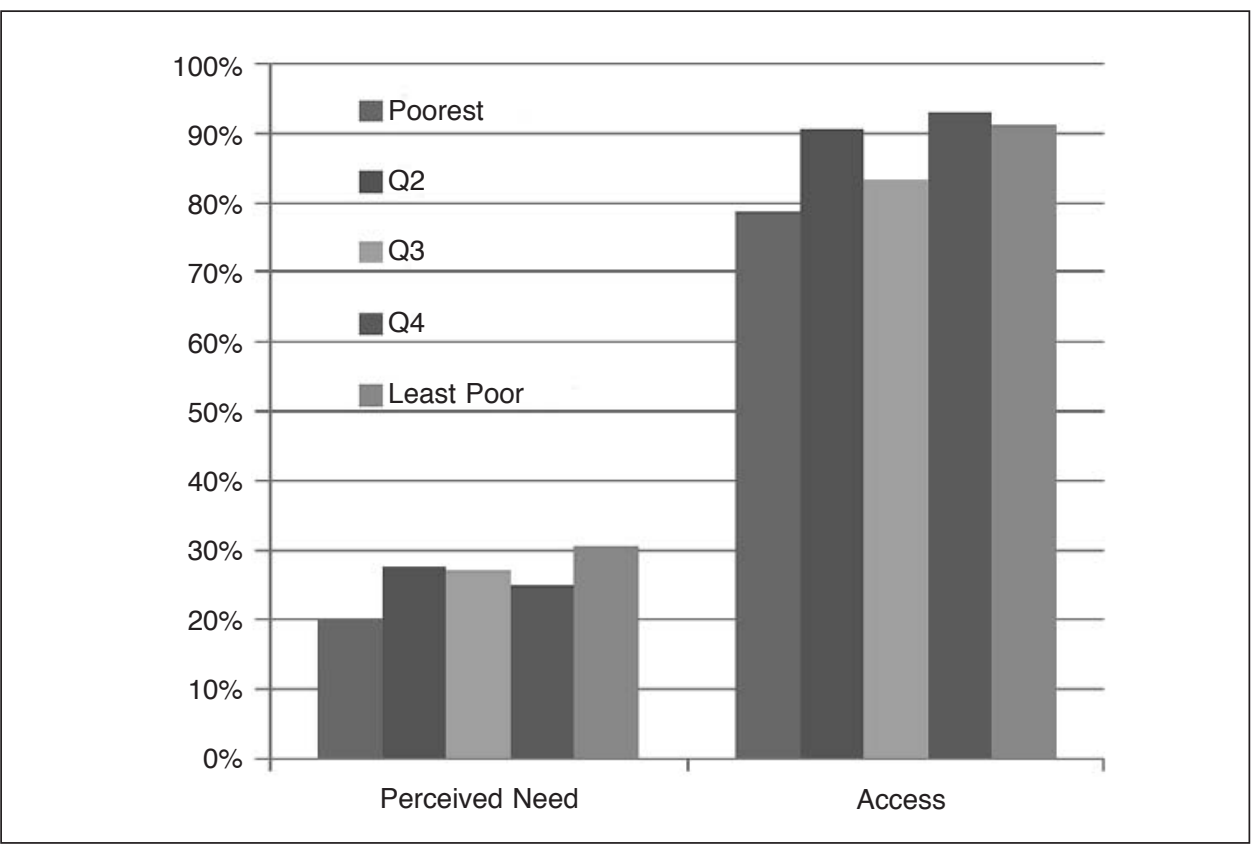

Figure 1. The gradient of perceived need and access to health care. ${ }^{a}$

aThe percentage of people with a "Perceived need" for health care, and the percentage of those reporting "Access" to health care shown separately by quintile of wealth.

not satisfactory and contributes to possible consumer's apathy towards the services. ${ }^{47,72}$ The appalling conditions of service for health care professionals in resource-poor countries have amply been documented in literature. ${ }^{73-78}$

It was shown (Figure 2) that those who accessed needed care did not access them from the same sources equally. The richest quintile accessed care as out-patients and the poorest accessed care at home. Interestingly, the poorest had the highest missing responses to this question. It is very likely that accessing care at home may have been self-medication, which is widespread in this part of the globe. ${ }^{79-82}$ Additionally, a good number of people patronise the traditional healing homes or herbalists. ${ }^{83-90}$ These local healers charge less than orthodox medical practitioners and are considered more knowledgeable for certain ailments. It is therefore not implausible that the poorest would opt for them. However, it has been reported that only one-fifth of the general population seek modern health care (orthodox medicine) in Burkina Faso, ${ }^{86} \mathrm{a}$ fact that alone speaks volumes.

In our study, men reported both more need and more access than women, but these differences were not statistically significant. However, gender has been reported to influence health, access to health care, and quality of care. ${ }^{91} \mathrm{~A}$ study that examined willingness to pay for community-based insurance found that men were more willing to pay than women. ${ }^{92}$ One might extrapolate from this that men were more likely also to pay out-of-pocket than women, and so should access more care. However, our results did not establish this as we found no significant difference between men and women. 


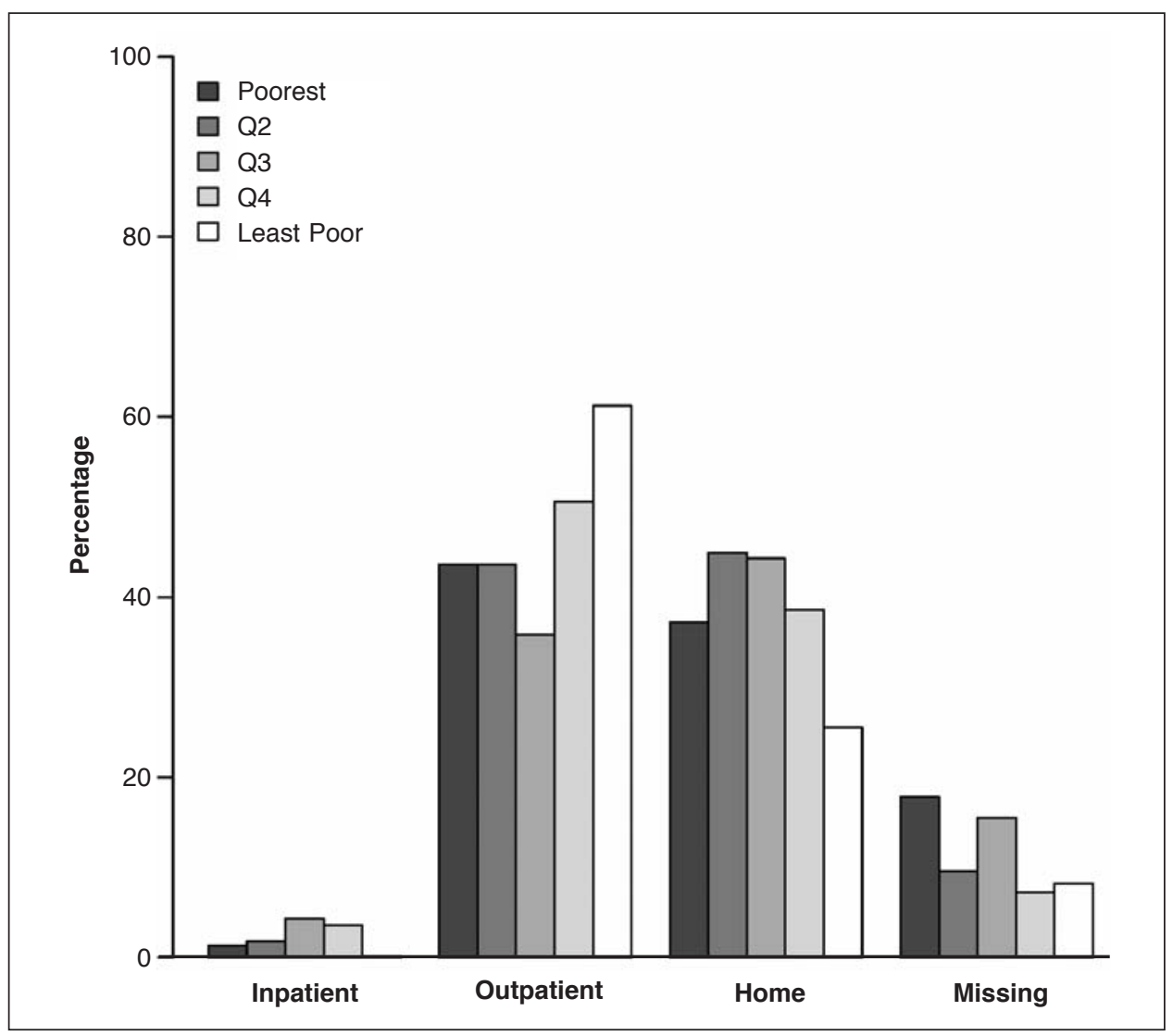

Figure 2. Percentage differences in the access to different sources of health care by quintile of wealth.

It is important to exercise a little bit of caution here. Willingness to pay could be a function of ability to pay. It may be that men are more able to pay than women and not that gender has any effect so to say on willingness to pay as such. This argument is supported by another study that reported that there was no significant difference in willingness-to-pay between men and women if they could read and write. ${ }^{92}$ In other words, it could indeed be education that actually influences both ability and willingness to pay. Although illiteracy is widespread in Burkina Faso, the female illiteracy rate is higher than the male..$^{92}$ Our model did not include education and current job status.

Noteworthy is our finding that gender differences were found on such determinants for perceived need as socioeconomic status, marital status, age group, and setting. On access to health care, gender differences were observed with respect to socioeconomic status, marital status, setting, and adult/child relative need for and/or access to care. Even though one may tend to interpret the findings based on the cumulative response, it may be more useful to investigate findings in terms of locally prevalent gender norms. For example, females are more likely than males to have reported accurately on children's health and ill-health. 
Those whose spouses had died reported more need for care than others even though they did not access more care. It is possible that predominantly being poor farmers, these people would not have enough money for health care when needed, being also encumbered by welfare of their children. In many African societies, widows are treated badly by the (extended) families of their deceased husbands. ${ }^{93-95}$ In certain tribes in Uganda, Nigeria, and Burkina Faso, widows are not allowed to inherit anything from their husbands. ${ }^{96}$ In Burkina Faso brothers-in-law may exclude their brother's widow from the household and its land. ${ }^{96}$ Widows are the most vulnerable in the society, and rank amongst the poorest. In fact, widowhood is emblematic of poverty. ${ }^{93-95,97-99}$ They experience ostracism, violence, homelessness, ill health, and discrimination. Their daughters may suffer multiple deprivations, which increase their vulnerability to abuse. Most widows are homeless and may not be captured in national censuses. In fact, the numbers of widows as a percentage of the female population is not known in most developing countries, for which estimates vary widely. ${ }^{100}$ Even poverty surveys may obscure inequities between individuals in a household; widows can actually live in poverty within relatively affluent households such as those which have been categorized as non-poor using PCA (as described earlier).

The link between ill health and poverty has long been established. ${ }^{101}$ It is therefore not surprising that widows reported more need than others, even though they didn't access the needed care. Cultural practices may require that a widow spends all the family's wealth seeking care for the dying husband and on the eventual funeral rites. Consequently, the family is dragged into indigence afterwards. Increasingly during the era of HIV/AIDS, this problem is becoming a concern, especially in the absence of any form of government-assisted programmes for the indigent.

In the present study, children were reported to have needed more care and to have accessed more care than adults, although previous work has reported that seeking professional care was similar for children and adults. ${ }^{102}$ Some other previous studies have documented that adult members of the households were prioritized in allocation of resources for health care because they ensure household production by working in the farms. ${ }^{60,103}$ These studies were localized in coverage and so may not be as representative of Burkina Faso as our study sample.

For children, it was stated that a decrease in utilization of health care has double negative effect on their health status: negative externalities of the diseases to the community (in case of preventable diseases), and the progression of the disease to the detriment of the individual child. ${ }^{60}$ From our results, it appears as a good development for public health in Burkina Faso that this vulnerable group is being served. However, another study argued that when price of care is high or income low, people are less likely to think of themselves and their children as ill, especially when there is no likelihood of actually seeking care because of prohibitive health care costs or due to unavailability of health care services and facilities. ${ }^{104}$ It would therefore be safe in the interpretation of our findings that we err on the side of caution.

Policy implications. It has been stated that the user fee seems to be a relatively weak policy tool because it focuses on patients rather than on provider behaviours. ${ }^{105}$ This view is based on the assumptions that demand for health care is inelastic. That is, people's concern for their health is relatively insensitive to the changes in the cost of 
care. However, a recent study found that user charges introduced in places at a time of deepening poverty have become great barriers to access for many, especially the less educated, women, and those who are economically disempowered. ${ }^{106}$ Another study, from China, found that some opportunity costs were inelastic (such as travel distance to facilities), but for direct costs price elasticity was higher, with the poorer people showing greater price sensitivity to cost than the wealthier people. ${ }^{107}$ The context of health care delivery appears to be a variable that requires closer examination in understanding the social gradients of demand and access. In Burkina Faso, there is a need to evaluate the cost-recovery efforts with access in mind, especially among the most poor.

This article raises more questions than it can answer. The results are from a crosssectional study of one of the economically poorest countries in the world, and one of the data-poorest countries in the world. The results differ sufficiently from a blanc mange social-gradients perspective that they support a call for further research. Ideally a multi-disciplinary approach would be taken looking at individual and household level health care need, perceived need, and utilisation employing both epidemiological, anthropological, economic, and geographical perspectives. Longitudinal data from largely observational studies as well as studies of policy interventions would inform an understanding of the causal mechanisms involved.

The call for more research, however, should not mean that communities should have to wait for more research before seeing action to improve conditions. Exploring alternative methods for financing health care delivery that would not compromise access for those who need health care is certainly the way to achieve equity in health. ${ }^{108}$ Those alternatives include state-assisted (free or highly subsidized) health care packages for the poor. The challenge would then be to ensure that health care for the poor is not poor health care.

\section{Notes}

1. Marmot M. Health in an unequal world. Lancet. 2006 Dec 9;368(9552):2081-94.

2. Marmot M, Commission on Social Determinants of Health. Achieving health equity: from root causes to fair outcomes. Lancet. 2007 Sep 29;370(9593):1153-63.

3. Murray CJ, Kulkarni SC, Michaud C, et al. Eight Americas: investigating mortality disparities across races, counties, and race-counties in the United States. PLoS Med. 2006 Sep;3(9):e260.

4. Victora CG, Wagstaff A, Schellenberg JA, et al. Applying an equity lens to child health and mortality: more of the same is not enough. Lancet. 2003 Jul 19;362(9379):233-41.

5. Solar O, Irwin A. A conceptual framework for action on the social determinants of health. Discussion paper for the Commission on Social Determinants of Health. Geneva, Switzerland: World Health Organization, 2007.

6. Gwatkin DR, Rutstein S, Johnson K, et al. Socio-economic differences in health, nutrition and population within developing countries: an overview. Niger J Clin Pract. 2007 Dec;10(4):272-82.

7. van Rossum CT, Shipley MJ, van de Mheen H, et al. Employment grade differences in cause specific mortality. A 25 year follow up of civil servants from the first Whitehall study. J Epidemiol Community Health. 2000 Mar;54(3):178-84.

8. Marmot MG, Smith GD, Stansfeld S, et al. Health inequalities among British civil servants: the Whitehall II study. Lancet. 1991 Jun 8;337(8754):1387-93. 
9. Marmot MG, Shipley MJ. Do socioeconomic differences in mortality persist after retirement? 25 year follow up of civil servants from the first Whitehall study. BMJ. 1996 Nov 9;313(7066):1177-80.

10. Razzaque A, Streatfield PK, Gwatkin DR. Does health intervention improve socioeconomic inequalities of neonatal, infant and child mortality? Evidence from Matlab, Bangladesh. Int J Equity Health. 2007 Jun 5;6:4.

11. Sen A. Health: perception versus observation. BMJ. 2002 Apr;324(7342):860-1.

12. Sen A. Why health equity? Health Econ. 2002 Dec;11(8):659-66.

13. Sen A. [Why should there be equity in health?] Rev Panam Salud Publica. 2002 May-Jun; 11(5-6):302-9.

14. Labonte R, Schreker T. Foreign policy matters: a normative view of the G8 and population health. Bull World Health Organ. 2007 Mar;85(3):185-91.

15. Assai M, Siddiqi S, Watts S. Tackling social determinants of health through community based initiatives. BMJ. 2006 Oct 21;333(7573):854-6.

16. Rashad H. Promoting global action on the social determinants of health. Diabetes Voice. 2006 Sep;51(3):33-5.

17. Irwin A, Valentine N, Brown C, et al. The commission on social determinants of health: tackling the social roots of health inequities. PLos Med. 2006 May;3(6):e106.

18. Subramanian SV, Subramanyam MA, Selvaraj S, et al. Are self-reports of health and morbidities in developing countries misleading? Evidence from India. Soc Sci Med. 2009 Jan;68(2):260-5. Epub 2008 Nov 18.

19. Kelleher CC, Harrington J, Friel S. Measures of self-reported morbidity according to age, gender and general medical services eligibility in the national survey of lifestyles, attitudes and nutrition. Ir J Med Sci. 2002 Jul-Sep;171(3):134-8.

20. Mathers CD, Douglas RM. Measuring progress in population health and wellbeing. In: Eckersley R, ed. Measuring progress: is life getting better? Collingwood, Australia: CSIRO Publishing, 1998:125-55.

21. Vagero D, Erikson R. Socioeconomic inequalities in morbidity and mortality in western Europe. Lancet. 1997 Aug;350(9076):516.

22. Erikson R, Torssander J. Social class and cause of death. Eur J Public Health. 2008 Oct;18(5):473-8. Epub 2008 Jun 18.

23. Fors S, Lennartsson C, Lundberg O. Health inequalities among older adults in Sweden 1991-2002. Eur J Public Health. 2008 Apr;18(2):138-43. Epub 2007 Oct 9.

24. Kuper H, Adami HO, Theorell T, et al. The socioeconomic gradient in the incidence of stroke: a prospective study in middle-aged women in Sweden. Stroke. 2007 Jan;38(1): 27-33. Epub 2006 Nov 30.

25. Merlo J, Gerdtham UG, Lynch J, et al. Social inequalities in health-do they diminish with age? Revisiting the question in Sweden 1999. Int J Equity Health. 2003 Mar $11 ; 2(1): 2$.

26. Burstrom B. Increasing inequalities in health care utilisation across income groups in Sweden during the 1990s? Health Policy. 2002 Nov;62(2):117-29.

27. Burstrom B, Bernhardt E. Social differentials in the decline of child mortality in nineteenth century Stockholm. Eur J Public Health. 2001 Mar;11(1):29-34.

28. Ringback Weitoft G, Hjern A, Batljan I, et al. Health and social outcomes among children in low-income families and families receiving social assistance-a Swedish national cohort study. Soc Sci Med. 2008;66(1):14-30. Epub 2007 Sep 24.

29. Gwatkin DR. IMCI: what can we learn from an innovation that didn't reach the poor? Bull World Health Organ. 2006 Oct;84(10):768. 
30. Gwatkin DR. How much would poor people gain from faster progress towards the millennium development goals for health? Lancet. 2005 Feb 26-Mar 4;365(9461): 813-7.

31. Moser KA, Leon DA, Gwatkin DR. How does progress towards the child mortality millennium development goal affect inequalities between the poorest and least poor? Analysis of Demographic and Health Survey data. BMJ. 2005 Nov 19;331(7526):11802. Epub 2005 Nov 11.

32. Gwatkin DR, Bhuiya A, Victora CG. Making health systems more equitable. Lancet. 2004 Oct 2-8;364(9441):1273-80.

33. Heuveline P, Guillot M, Gwatkin DR. The uneven tides of the health transition. Soc Sci Med. 2002 Jul;55(2):313-22.

34. Gwatkin DR, Guillot M, Heuveline P. The burden of disease among the global poor. Lancet. 1999 Aug 14;354(9178):586-9.

35. Gwatkin DR. Health inequalities and the health of the poor: what do we know? What can we do? Bull World Health Organ. 2000;78(1):3-18.

36. Graham H. Tackling health inequalities in England: remedying health disadvantages, narrowing gaps or reducing health gradients? J Soc Policy. 2004 Feb;33(1):115-31.

37. Kelly MP, Morgan A, Bonnefoy J, et al. The social determinants of health: developing an evidence base for political action. Geneva, Switzerland: World Health Organization, 2007.

38. Caldwell JC. Education as a factor in mortality decline: an examination of Nigerian data. Popul Stud. 1979;33(3):395-413.

39. Bicego GT, Boerma JT. Maternal education and child survival: a comparative study of survey data from 17 countries. Soc Sci Med. 1993 May;36(9):1207-27.

40. Abdulraheem IS. Health needs assessment and determinants of health-seeking behaviour among elderly Nigerians: a house-hold survey. Ann Afr Med. 2007 Jun;6(2): 58-63.

41. Bloom G. Primary health care meets the market in China and Vietnam. Health Policy. 1998 Jun;44(3):233-52.

42. Onwujekwe O, Hanson K, Fox-Rushby J. Inequalities in purchase of mosquito nets and willingness to pay for insecticide-treated nets in Nigeria: challenges for malaria control interventions. Malar J. 2004 Mar 16;3:6.

43. Rosenzweig MR, Schultz TP. Child mortality and fertility in Colombia: individual and community effects. Health Policy Educ. 1982 Mar;2(3-4):305-48.

44. Schellenberg JA, Victora CG, Mushi A, et al. Inequities among the very poor: health care for children in rural southern Tanzania. Lancet. 2003 Feb 15;361(9357):561-6.

45. Wiseman V, Scott A, Conteh L, et al. Determinants of provider choice for malaria treatment: experiences from The Gambia. Soc Sci Med. 2008 Aug;67(4):487-96. Epub 2008 Jun 5.

46. Reidpath DD, Allotey P. Measuring global health inequity. Int J Equity Health. 2007 Oct 30;6:16.

47. Haddad S, Nougtara A, Fournier P. Learning from health system reforms: lessons from Burkina Faso. Trop Med Int Health. 2006 Dec;11(12):1889-97.

48. United Nations Development Programme (UNDP). Human development report 1990: concept and measurement of human development. New York, NY: UNDP, 1990. Available at: http://hdr.undp.org/en/reports/global/hdr1990/.

49. United Nations Development Programme (UNDP). Human development report 2004: cultural liberty in today's diverse world. New York, NY: UNDP, 2004. Available at: http://hdr.undp.org/en/reports/global/hdr2004/. 
50. United Nations Development Programme (UNDP). Human development report 2007/8: fighting climate change: human solidarity in a divided world. New York, NY: UNDP, 2008. Available at: http://hdr.undp.org/en/reports/global/hdr2007-2008/.

51. Bodart C, Servais G, Mohamed YL, et al. The influence of health sector reform and external assistance in Burkina Faso. Health Policy Plan. 2001 Mar;16(1):74-86.

52. Ustun TB, Chatterji S, Villanueva M, et al. WHO multi-country survey study on health and responsiveness 2000-2001. Geneva, Switzerland: WHO, 2001. Available at: http://www.who.int/healthinfo/survey/whspaper37.pdf.

53. Filmer D, Pritchett LH. Estimating wealth effects without expenditure data-or tears: an application to educational enrollments in states of India. Demography. 2001 Feb;38(1):115-32.

54. StataCorp. Stata statistical software: release 10. College Station, TX: StataCorp LP, 2007.

55. Develay A, Sauerborn R, Diesfeld HJ. Utilization of health care in an Africa urban area: result from a household survey in Ouagadougou, Burkina Faso. Soc Sci Med. 1996 Dec;43(11):1611-9.

56. Mataria A, Luchini S, Daoud Y, et al. Demand assessment and price-elasticity estimation of quality-improved primary health care in Palestine: a contribution from the contingent valuation method. Health Econ. 2007 Oct;16(10):1051-68.

57. Pokhrel S, Hidayat B, Flessa S, et al. Modelling the effectiveness of financing policies to address underutilization of children's health services in Nepal. Bull World Health Organ. 2005 May;83(5):338-44. Epub 2005 Jun 24.

58. Richard V. [Funding for health care in sub-Saharan Africa-cost recovery.] Med Trop (Mars). 2004;64(4):337-40.

59. Ching P. User fees, demand for children's health care and access across income groups: the Philippine case. Soc Sci Med. 1995 Jul;41(1):37-46.

60. Sauerborn R, Nougtara A, Latimer E. The elasticity of demand for health care in Burkina Faso: differences across age and income groups. Health Policy Plan. 1994 Jun;9(2): 185-92.

61. Dong H, Gbangou A, De Allegri M, et al. The differences in characteristics between health-care users and non-users: implication for introducing community-based health insurance in Burkina Faso. Eur J Health Econ. 2008 Feb;9(1):41-50. Epub 2006 Dec 21.

62. De Allegri M, Sanon M, Bridges J, et al. Understanding consumers' preferences and decision to enrol in community-based health insurance in rural West Africa. Health Policy. 2006 Mar;76(1):58-71. Epub 2005 Jun 8.

63. Dong H, Kouyate B, Cairns J, et al. Differential willingness of household heads to pay community-based health insurance premia for themselves and other household members. Health Policy Plan. 2004 Mar;19(2):120-6.

64. Dong H, Kouyate B, Cairns J, et al. Willingness-to-pay for community-based insurance in Burkina Faso. Health Econ. 2003 Oct;12(10):849-62.

65. McIntyre D, Thiede M, Dahlgren G, et al. What are the economic consequences for households of illness and of paying for health care in low- and middle-income country contexts? Soc Sci Med. 2006 Feb;62(4):858-65. Epub 2005 Aug 15.

66. Stanton B, Clemens J. User fees for health care in developing countries: a case study of Bangladesh. Soc Sci Med. 1989;29(10):1199-205.

67. Litvack JI, Bodart C. User fees plus quality equals improved access to health care: results of a field experiment in Cameroon. Soc Sci Med. 1993 Aug;37(3):369-83. 
68. Luong DH, Tang S, Zhang T, et al. Vietnam during economic transition: a tracer study of health service access and affordability. Int J Health Serv. 2007;37(3):573-88.

69. Segall M, Tipping G, Lucas H, et al. Economic transition should come with a health warning: the case of Vietnam. J Epidemiol Community Health. 2002 Jul;56(7): 497-505.

70. Sepehri A, Chernomas R, Akram-Lodhi AH. If they get sick, they are in trouble: health care restructuring, user charges, and equity in Vietnam. Int J Health Serv. 2003; 33(1):137-61.

71. Pokhrel S, Sauerborn R. Medical spending and health outcome in Nepal: problems with technology or its distribution? Bull World Health Organ. 2003;81(11):844-5. Epub 2004 Jan 20.

72. Baltussen RM, Ye Y, Haddad S, et al. Perceived quality of care of primary health care services in Burkina Faso. Health Policy Plan. 2002 Mar;17(1):42-8.

73. Narasimhan V, Brown H, Pablos-Mendez A, et al. Responding to the global human resources crisis. Lancet. 2004 May 1;363(9419):1469-72.

74. Zijlstra EE. [Emigration of physicians from Africa: focus on Malawi.] Ned Tijdschr Geneeskd. 2008 Apr 26;152(17):1015-9.

75. Nabyonga-Orem J, Karamagi H, Atuyambe L, et al. Maintaining quality of health services after abolition of user fees: a Uganda case study. BMC Health Serv Res. 2008 May 9;8:102.

76. Muula AS, Maseko FC. How are health professionals earning their living in Malawi? BMC Health Serv Res. 2006 Aug 9;6:97.

77. Muula AS. Is there any solution to the "brain drain" of health professionals and knowledge from Africa? Croat Med J. 2005 Feb;46(1):21-9.

78. Schneider H, Blaauw D, Gilson L, et al. Health systems and access to antiretroviral drugs for HIV in Southern Africa: service delivery and human resources challenges. Reprod Health Matters. 2006 May;14(27):12-23.

79. Ouedraogo LT, Some IT, Diarra M, et al. [Self-medication in the treatment of acute malaria: study based on users of private health drug stores in Ouagadougou, Burkina Faso.] Bull Soc Pathol Exot. 2008 Apr;101(2):124-7.

80. Pfeiffer K, Some F, Muller O, et al. Clinical diagnosis of malaria and the risk of chloroquine self-medication in rural health centres in Burkina Faso. Trop Med Int Health. 2008 Mar;13(3):418-26.

81. Varenne B, Petersen PE, Fournet F, et al. Illness-related behaviour and utilization of oral health services among adult city-dwellers in Burkina Faso: evidence from a household survey. BMC Health Serv Res. 2006 Dec 27;6:164.

82. Koueta F, Dao L, Ye D, et al. [Risk factors for death from severe malaria in children at the Charles de Gaulle pediatric hospital of Ouagadougou (Burkina Faso).] Sante. 2007 Oct-Dec;17(4):195-9.

83. Beiersmann C, Sanou A, Wladarsch E, et al. Malaria in rural Burkina Faso: local illness concepts, patterns of traditional treatment and influence on health-seeking behaviour. Malar J. 2007 Aug 8;6:106.

84. Ye D, Nacro N, Koueta F, et al. [Traditional practice of infant care: investigation of 502 mothers and infants in Ouagadougou (Burkina Faso).] Arch Pediatr. 2007 Sep;14(9):1112-3. Epub 2007 Jul 3.

85. Meda N, Bognounou V, Seni E, et al. [Cataract in Burkina Faso: factors of choice between modern and traditional surgical procedures.] Med Trop (Mars). 2005 Nov; 65(5):473-6. 
86. Baltussen R, Ye Y. Quality of care of modern health services as perceived by users and non-users in Burkina Faso. Int J Qual Health Care. 2006 Feb;18(1):30-4. Epub 2005 Oct 18.

87. Tapsoba H, Deschamps JP. Use of medicinal plants for the treatment of oral diseases in Burkina Faso. J Ethnopharmacol. 2006 Mar 8;104(1-2):68-78. Epub 2005 Oct 7.

88. Mueller $\mathrm{O}$, Razum $\mathrm{O}$, Traore $\mathrm{C}$, et al. Community effectiveness of chloroquine and traditional remedies in the treatment of young children with falciparum malaria in rural Burkina Faso. Malar J. 2004 Oct 20;3:36.

89. Millogo A, Ratsimbazafy V, Nubukpo P, et al. Epilepsy and traditional medicine in Bobo-Dioulasso (Burkina Faso). Acta Neurol Scand. 2004 Apr;109(4):250-4.

90. Huygens P, Konate B, Traore A, et al. [Traditional enema for newborns and infants in Bobo Dioulasso: health practice or socialisation.] Sante. 2002 Oct-Dec;12(4): 357-62.

91. World Health Organization (WHO). Gender and health: technical paper. Geneva, Switzerland: WHO, 1998. Available at: http://www.who.int/docstore/gender-and-health/ pages/WHO\%20-\%20Gender\%20and\%20Health\%20Technical\%20Paper.htm.

92. Dong H, Kouyate B, Snow R, et al. Gender's effect on willingness-to-pay for community-based insurance in Burkina Faso. Health Policy. 2003 May;64(2): 153-62.

93. Onadeko MO, Lawoyin T, Amodu MO, et al. Problems of widowhood: a study of widows in a tertiary institution in Ibadan, south west Nigeria. Afr J Med Med Sci. 2002 Sep;31(3):201-6.

94. D’Souza S. Poverty among widows of Kinshasa, Congo. J Health Popul Nutr. 2000 Sep; 18(2):79-84.

95. Rosenblatt PC, Nkosi BC. South African Zulu widows in a time of poverty and social change. Death Stud. 2007 Jan-Feb;31(1):67-85.

96. Owen M. A world of widows. London, United Kingdom: Zed Books, 1997.

97. Angel JL, Jimenez MA, Angel RJ. The economic consequences of widowhood for older minority women. Gerontologist. 2007 Apr;47(2):224-34.

98. McGarry K, Schoeni RF. Medicare gaps and widow poverty. Soc Secur Bull. 2005;66(1): 58-74.

99. McGarry K, Schoeni RF. Widow(er) poverty and out-of-pocket medical expenditures near the end of life. J Gerontol B Psychol Sci Soc Sci. 2005 May;60(3):S160-8.

100. United Nations. Widowhood: invisible women, secluded or excluded. Women 2000. 2001 Dec:2-20. Available at: http://www.un.org/womenwatch/daw/public/wom_Dec\% 2001\%20single\%20pg.pdf.

101. Halder AK, Kabir M. Child mortality inequalities and linkage with sanitation facilities in Bangladesh. J Health Popul Nutr. 2008 Mar;26(1):64-73.

102. Sue S, Dhindsa MK. Ethnic and racial health disparities research: issues and problems. Health Educ Behav. 2006 Aug;33(4):459-69.

103. Sauerborn R, Berman P, Nougtara A. Age bias, but no gender bias, in the intrahousehold resource allocation for health care in rural Burkina Faso. Health Transit Rev. 1996 Oct;6(2):131-45.

104. Pokhrel S. Determinants of parental reports of children's illnesses: empirical evidence from Nepal. Soc Sci Med. 2007 Sep;65(6):1106-17. Epub 2007 Jun 19.

105. Uzochukwu BS, Onwujekwe OE. Socio-economic differences and health seeking behaviour for the diagnosis and treatment of malaria: a case study of four local gov- 
ernment areas operating the Bamako initiative programme in south-east Nigeria. Int J Equity Health. 2004 Jun 17;3(1):6.

106. Lanre-Abass BA. Poverty and maternal mortality in Nigeria: towards a more viable ethics of modern medical practice. Int J Equity Health. 2008 Apr 30;7:11.

107. Qian D, Pong RW, Yin A, et al. Determinants of health care demand in poor, rural China: the case of Gansu Province. Health Policy Plan. 2009 Sep;24(5):324-34. Epub 2009 May 8.

108. Akpede GO, Omotara BA, Gazali W. Severity signs of childhood diarrhoea in north eastern Nigeria. J R Soc Health. 1995 Jun;115(3):164-8, 173-4. 